\title{
Development of a multidisciplinary consultation in pediatric rheumatology in Switzerland with a link to daily life of the patient B Fonjallaz*1, A Utiger ${ }^{1}$, G Aubel ${ }^{1}$, E Roux ${ }^{2}$ and MF Hofer ${ }^{1}$
}

\author{
Address: ${ }^{1}$ Pediatric Rheumatology of Suisse Romande, Lausanne and Geneva, Switzerland and ${ }^{2}$ Geneva League against Rheumatism, Geneva, \\ Switzerland \\ * Corresponding author
}

\author{
from I5th Paediatric Rheumatology European Society (PreS) Congress \\ London, UK. 14-17 September 2008 \\ Published: 15 September 2008 \\ Pediatric Rheumatology 2008, 6(Suppl I):PI66 doi:I0.II86/I546-0096-6-SI-PI66
}

This abstract is available from: http://www.ped-rheum.com/content/6/SI/PI66

(C) 2008 Fonjallaz et al; licensee BioMed Central Ltd.

\section{Background}

Pediatric patients consulting a rheumatologist are suffering from chronic diseases leading to a decreased quality of life associated with fears and many daily life problems.

\section{Aim}

We developed a multidisciplinary approach to help the patients and their parents in their daily life with the disease and try to improve their quality of life.

\section{Methods}

We established a multidisciplinary network in the French part of Switzerland, within and outside the hospital, with pediatric rheumatologists, nurses, physical therapists and occupational therapists. The patients are seen by the different members of the team according to their needs, and after consent of the physician, patient and parents. The nurses are providing a link between the consultation and the daily life of the child (family, home, school). With the different members of the team, we evaluated the needs of the patients and the goals of the network.

\section{Results}

We identified different items for patients' needs: support, help, information, prevention, teaching for the patient and the family; and for the goals of the network: best integration of the child (school, daily activities), autonomy of the patient and his family, improve the quality of life, create a link between the different professionals to improve the outcome of the therapies.

\section{Conclusion}

By establishing a multidisciplinary approach of care for the children with rheumatic diseases, we identified the items, which are to our opinion the most pertinent in order to improve the quality of the care to these patients. 